DR DAVID BERARDAN (Orcid ID : 0000-0002-2682-998X)

Article type : Article

\title{
Charge compensation mechanisms in Li-substituted high-entropy oxides and influence on Li superionic conductivity
}

N. Osenciat ${ }^{1}$, D. Bérardan ${ }^{1^{*}}$, D. Dragoe ${ }^{1}$, B. Léridon ${ }^{2}$, S. Holé ${ }^{2}$, A.K. Meena ${ }^{1}$, S. Franger ${ }^{1}$, N. Dragoe ${ }^{1^{*}}$

1. ICMMO (UMR CNRS 8182), Univ. Paris-Sud, Univ. Paris-Saclay, F-91405, Orsay, France

2. LPEM (UMR CNRS 8213, ESPCI-Paris, PSL Université, Sorbonne Université, F-75005, Paris, France

Corresponding Authors:

David Bérardan, david.berardan@u-psud.fr

Nita Dragoe, nita.dragoe@u-psud.fr

\section{Abstract}

The charge compensation mechanisms that occurs when $\mathrm{Li}^{+}$substitutes a $2+$ element in superionic conductor (MgCoNiCuZn)O high entropy oxide have been studied using a combination of thermogravimetric analysis and X-ray photoemission spectroscopy. Depending on the concentration of $\mathrm{Li}^{+}$in the compound, the charge compensation involves first partial oxidation of $\mathrm{Co}^{2+}$ into $\mathrm{Co}^{3+}$ for

This article has been accepted for publication and undergone full peer review but has not been through the copyediting, typesetting, pagination and proofreading process, which may lead to differences between this version and the Version of Record. Please cite this article as doi: $10.1111 /$ jace. 16511

This article is protected by copyright. All rights reserved. 
low fraction of $\mathrm{Li}^{+}$, and then a combination of both the oxidation of cobalt and the formation of oxygen vacancies for large fraction of $\mathrm{Li}^{+}$.

\section{Introduction}

Lithium ion batteries remain of huge interest for many different applications and at various scales, including consumer portable electronics (cell phones, laptops), automotive propulsion, or mass energy storage for intermittent power generation systems. One of the challenges that still have to be solved is the development of efficient and safe electrolytes to replace the non-aqueous liquid electrolytes used to date ${ }^{1}$. A promising direction is the use of solid state electrolytes, which would eliminate the need for liquid confinement and make the cells design simpler. The main difficulty is the development of solid state $\mathrm{Li}^{+}$conductors exhibiting Li-conductivity comparable to that of liquid electrolytes close to room temperature ${ }^{2}$.

Our team has recently shown the promising properties of high-entropy oxides (HEOx) as solid state alkali-conductors, with room temperature ionic conductivity values reaching $1 \mathrm{mS} . \mathrm{cm}^{-1}$ at $20^{\circ} \mathrm{C}$ in $(\mathrm{MgCoNiCuZn})_{0.7} \mathrm{Li}_{0.3} \mathrm{O}$, increasing to $4 \mathrm{mS}^{\mathrm{cm}} \mathrm{cm}^{-1}$ at $80^{\circ} \mathrm{C}^{3}$. High-entropy oxides constitute a new class of materials that has been discovered recently, extending to oxides the concept of high-entropy materials that was known for long in the case of alloys ${ }^{4}$. They are obtained by mixing at least 5 binary oxides and heating them at high temperature, larger than $875^{\circ} \mathrm{C}$ in ref. 4 , followed by quenching. When the temperature is large enough, the entropy of configuration becomes the main component of the total Gibbs energy $\Delta r G=\Delta r H-T \Delta r S$. Thus, instead of forming a mixture of several phases and being driven by the enthalpy of formation, the system crystallizes in a metastable simple solid solution that can be frozen at room temperature by quenching. Typically in the case of (MgCoNiCuZn)O, the first canonical composition reported in 2015 by Rost et al., a simple rocksalt structure where the cations are distributed randomly on the cationic sublattice is formed when a

This article is protected by copyright. All rights reserved. 
mixture of the binary constituents is heated above $875^{\circ} \mathrm{C}$, and the resulting entropy-stabilized structure decomposes if further annealed below $875^{\circ} \mathrm{C}{ }^{4}$. Other structures have been observed since 2015 with other compositions, including perovskite ${ }^{5,6}$ or fluorite structures ${ }^{7}$. We have shown previously that the rocksalt phase obtained in the case of (MgCoNiCuZn)O is very robust against substitutions, due to charge compensation mechanism(s) that keep the charge balance between the cationic and anionic sublattices ${ }^{8}$. Therefore, when substituting part of the $2+$ cations by $\mathrm{Li}^{+}$to form $(\mathrm{MgCoNiCuZn})_{1-\mathrm{x}} \mathrm{Li}_{x} \mathrm{O}$, the rocksalt structure is maintained up to at least $\mathrm{x}=0.3$ and the materials remain electrically insulating. However, a Li-conduction emerges, which increases with the fraction of lithium (note that the same phenomenon was also observed with sodium) ${ }^{3}$. To date, the conduction mechanism of $\mathrm{Li}^{+}$ions in this material remains unknown. Our preliminary studies showed that the charge compensation mechanism occurring upon Li-substitution may include a combination of oxygen vacancies and/or $3+$ cations formation ${ }^{3}$. As the understanding of this charge compensation mechanism could shed some light on the Li-conduction mechanism (and thus help improving the Li-conductivity in this system), we report here on the evolution of the oxygen stoichiometry and of the valence state of the cations as a function of the lithium content in Lisubstituted (MgCoNiCuZn)O, and on their influence of the lithium ionic conductivity as a function of temperature.

\section{Experimental details}

All samples with nominal compositions $(\mathrm{MgCoNiCuZn})_{1-\mathrm{x}} \mathrm{Li}_{\mathrm{x}} \mathrm{O}(\mathrm{x}=0$ to 0.3$)$ were synthesized from stoichiometric mixtures of oxides and carbonate precursors: MgO (Alfa Aesar 99.95\%), CuO (Alfa Aesar 99.7\%), $\mathrm{NiO}$ (Strem Chemicals 4N), $\mathrm{CO}_{3} \mathrm{O}_{4}$ (Alfa Aesar 99.7\%), $\mathrm{ZnO}$ (Alfa Aesar $4 \mathrm{~N}$ ) and $\mathrm{Li}_{2} \mathrm{CO}_{3}$ (Alfa Aesar 99.998\%). Starting powders of these precursors with a total mass of $4 \mathrm{~g}$ were mixed using an agate mortar and pestle followed by ball milling using a Fritsch Pulverisette 7 Premium Line at $350 \mathrm{rpm}$ during $1 \mathrm{~h}$. The resulting mixture was uniaxially pressed into bar-shaped pellets $\left(3 \times 12 \mathrm{~mm}^{2}\right)$

This article is protected by copyright. All rights reserved. 
under $250 \mathrm{MPa}$. Part of these pellets were used for thermogravimetric analysis (TGA), and the other ones were heated at $950^{\circ} \mathrm{C}$ in air during $12 \mathrm{~h}$ in an alumina crucible with a heating rate of $75^{\circ} \mathrm{C} \cdot \mathrm{h}^{-1}$ from room temperature to $400^{\circ} \mathrm{C}$ and then $200^{\circ} \mathrm{C} \cdot \mathrm{h}^{-1}$ until $950^{\circ} \mathrm{C}$ followed by quenching in liquid nitrogen. The geometrical density of the resulting samples was between $75-80 \%$ of the theoretical density.

Room temperature powder X-ray diffraction (XRD) patterns were collected using a Panalytical X'Pert diffractometer with a $\mathrm{Ge}(111)$ incident monochromator ( $\mathrm{CU}-\mathrm{K} \alpha 1$ radiation) and X'celerator detector. The lattice parameters were obtained by refining the resulting diffraction patterns using FULLPROF software ${ }^{9}$.

Thermogravimetric analysis (TGA) was performed using a Setaram Setsys Evo under flowing oxygen in the temperature range from room temperature to $950^{\circ} \mathrm{C}$ with a heating rate of $5 \mathrm{~K} \cdot \mathrm{min}^{-1}$. After $4 \mathrm{~h}$ at $950^{\circ} \mathrm{C}$, the samples were cooled down to room-temperature at $50 \mathrm{~K} \cdot \mathrm{min}^{-1}$. Post-TGA XRD patterns confirmed that the thermal treatment performed during the thermogravimetric analysis enabled the formation of the rocksalt phase, except for a slight widening of the Bragg peaks as the cooling speed was not large enough to perfectly freeze the high-temperature metastable structure. As some of the precursors were slightly hydrated, the actual weight loss occurring during the synthesis of the highentropy phase for each composition (due to the loss of $\mathrm{O}_{2}$ and $\mathrm{CO}_{2}$ ) was obtained by subtracting the combined weight losses of its constituting precursors (due to the loss of $\mathrm{H}_{2} \mathrm{O}$ ) to the absolute weight loss recorded during the analysis as described in supplementary information.

XPS analyses were performed on a Thermo Scientific K-Alpha XPS instrument with a monochromatic Al- $\mathrm{K}_{\alpha} \mathrm{X}$-ray source (energy $1486.68 \mathrm{eV}$ ) and hemispherical analyzer. Samples were fixed on the support using adhesive conducting tape. The pressure in the analysis chamber was below $2 \times 10^{-9}$ mbar and the diameter of the X-ray beam spot was $200 \mu \mathrm{m}$, corresponding to an irradiated surface of approximately $0.5 \mathrm{~mm}^{2}$. The hemispherical analyzer was operated at $0^{\circ}$ take off angle in the Constant Analyzer Energy (CAE) mode. Wide scan spectra were recorded at a pass energy of $200 \mathrm{eV}$

This article is protected by copyright. All rights reserved. 
and an energy step of $1 \mathrm{eV}$ while narrow scan spectra were recorded at a pass energy of $50 \mathrm{eV}$ and an energy step of $0.1 \mathrm{eV}$. Charge compensation was achieved by means of a "dual beam" flood gun, using low energy electrons ( $5 \mathrm{eV})$ and argon ions.

The recorded spectra were processed by means of the Avantage software, using a peak-fitting routine with Shirley background and symmetrical 70\%-30\% mixed Gaussian-Lorentzian peak shapes. The atomic ratios were evaluated following normalizations of the peak areas with the Scofield sensitivity factors.

The binding energy scale was calibrated on the neutral carbon set at $284.8 \mathrm{eV}$.

Electrochemical impedance spectroscopy (EIS) measurements were performed on samples contacted using silver wire two-probe contacts glued with silver paint. A $100 \mathrm{mV}$ AC perturbation was applied in the frequency range from $10 \mathrm{MHz}$ to $10 \mathrm{mHz}$ (Solartron 1296 Dielectric interface and a Solartron 1260 impedance/gain phase analyzer), at temperatures ranging from $100 \mathrm{~K}$ and $400 \mathrm{~K}$ (with 20K steps and a heating rate of $10 \mathrm{~K} \cdot \mathrm{min}^{-1}$ ) in a Quantum Design PPMS chamber under helium atmosphere (8 Torr). All the contacted surfaces were previously coated with copper (about $1000 \AA$ for each face by evaporation).The samples were systematically kept at the chosen temperature for 10 min for stabilization before starting the measurement process ( 3 EIS measurements performed at each temperature step).

DC ionic conductivity was estimated from the real part of the complex conductivity at low frequencies (constant value of $\sigma^{\prime}(\mathrm{f})$ in a large logarithmic range) by following the formula $\sigma^{*}(\mathrm{f})=\frac{e}{s}$. $\frac{1}{Z^{*}(f)}$ ( with typical the dimensional factor $\frac{e}{S} \approx 65 \mathrm{~m}^{-1}$ ).

This article is protected by copyright. All rights reserved. 


\section{Results and discussion}

After quenching from $950^{\circ} \mathrm{C}$ in liquid nitrogen, all samples belonging to the series (MgCoNiCuZn) ${ }_{x} \mathrm{Li}_{x} \mathrm{O}(\mathrm{x}=0$ to 0.3$)$ are essentially single phase (less than $1 \%$ secondary phase from XRD patterns) and crystallize in a rocksalt structure, which is consistent with our previous studies ${ }^{3}$. The lattice parameter strongly depends on the concentration of lithium, with a significant decrease as the concentration of $\mathrm{Li}$ increases, as shown in figure 1. Although the ionic radius of $\mathrm{Li}^{+}$in octahedral environment is larger than the ionic radius of any of the $\mathrm{M}^{2+}$ cation constituting the material, this decrease is consistent with a charge compensation mechanism involving either the oxidation of part of the $\mathrm{M}^{2+}$ cations (cobalt or nickel) into $\mathrm{M}^{3+}$ or oxygen vacancies. From figure 1 , two distinct regions with linear dependence of the lattice parameter on $\left[\mathrm{Li}^{+}\right]$are observed, having two different slopes. Therefore, it can be reasonably assumed that two distinct charge compensation mechanisms (either the oxidation of $\mathrm{M}^{2+}$ cations or oxygen vacancies) are at play below and above this limit, or two distinct combinations of such mechanisms.

As the synthesis is performed in air, there is a continual thermodynamic equilibrium between the oxygen contained in the precursors (or in the samples) and the surrounding environment. Therefore, depending on the charge compensation mechanism, the ideal reactions of formation of the compounds can be written as:

$$
\text { (1) } \begin{aligned}
& \frac{1-x}{5}\left(\mathrm{MgO}+\frac{1}{3} \mathrm{Co}_{3} \mathrm{O}_{4}+\mathrm{NiO}+\mathrm{CuO}+\mathrm{ZnO}\right)+\frac{x}{2} \mathrm{Li}_{2} \mathrm{CO}_{3} \rightarrow \\
& (\mathrm{Mg}, \mathrm{Ni}, \mathrm{Cu}, \mathrm{Zn})_{\frac{4(1-x)}{5}} \mathrm{Co}^{I I} \frac{1-6 x}{5} \mathrm{Co}^{I I I}{ }_{x} \mathrm{Li}_{x} \mathrm{O}+\frac{x}{2} \mathrm{CO}_{2}+\left(\frac{1}{30}-\frac{17}{60} x\right) \mathrm{O}_{2}
\end{aligned}
$$

This article is protected by copyright. All rights reserved. 
(2) $\frac{1-x}{5}\left(\mathrm{MgO}+\frac{1}{3} \mathrm{Co}_{3} \mathrm{O}_{4}+\mathrm{NiO}+\mathrm{CuO}+\mathrm{ZnO}\right)+\frac{x}{2} \mathrm{Li}_{2} \mathrm{CO}_{3} \rightarrow$

$$
(\mathrm{Mg}, \mathrm{Co}, \mathrm{Ni}, \mathrm{Cu}, \mathrm{Zn})_{1-x} \mathrm{Li}_{x} \mathrm{O}_{1-\frac{x}{2}} \square_{\frac{x}{2}}+\frac{x}{2} \mathrm{CO}_{2}+\frac{1-x}{30} \mathrm{O}_{2}
$$

with case 1 corresponding to the formation of $\mathrm{Co}^{3+}$ and case 2 to the formation of oxygen vacancies (the weight loss corresponding to case 1 would be the same with the formation of $\mathrm{Ni}^{3+}$ instead of $\mathrm{Co}^{3+}$. However, $\mathrm{Co}^{3+}$ are more likely to form than $\mathrm{Ni}^{3+}$ based on thermodynamic data, as $\mathrm{Co}^{3+}$ is generally more stable in octahedral environment than $\mathrm{Ni}^{3+10,11}$ ). The square symbol in equation 2 corresponds to oxygen vacancies in the anionic sublattice of the high-entropy rocksalt phase. The weight loss occurring during the synthesis differs between these two mechanisms, and it can be monitored using TGA. In figure 2, the black line corresponds to a simulation of the weight loss occurring during the synthesis assuming mechanism (1) alone whereas the red line corresponds to a simulation assuming mechanism (2) alone (a combination of both mechanisms would result in an experimental weight loss lying between these two lines). The dots correspond to the experimental weight loss corrected from the hydration of the precursors (see supplementary information). Below $\mathrm{x}=0.21$, the dots are very close to the black line, which means that when $\mathrm{Li}^{+}$is introduced in (MgCoNiCuZn)O, the charges are first compensated by the formation of $\mathrm{M}^{3+}$ (which could be $\mathrm{Co}^{3+}$ like described in mechanism $1, \mathrm{Ni}^{3+}$, or a combination of both). However, when the concentration of $\mathrm{Li}^{+}$ in the compound becomes larger than $x=0.21$, the dots gradually depart from the black line, meaning that a second mechanism is at play. In figure 2 , the blue line corresponds to a simulation of the weight loss that would occur during the synthesis assuming that $\mathrm{Co}^{3+}$ ions are formed until all $\mathrm{Co}^{2+}$ have been turned into $\mathrm{Co}^{3+}$ (or respectively $\mathrm{Ni}^{3+}$ and $\mathrm{Ni}^{2+}$ ) and that oxygen vacancies are formed above this limit. As expected, the blue line and the black line intercept at $x=1 / 6$ (when the fraction of lithium and cobalt are the same), and the experimental points do not fall on the simulation. However, the increase of the weight loss above $x=0.21$ is almost parallel to the blue line, which indicates that oxygen vacancies form above a critical concentration of lithium while the valence state of the cations does not change any more. Therefore, a free parameter was introduced to fit the data,

This article is protected by copyright. All rights reserved. 
corresponding to the fraction of cations turning from $2+$ to $3+$ (it should be noticed here that the charge compensation by a cation turning from $3+$ to $4+$, which is possible for cobalt, would be the same). The corresponding fit is plotted as the green line in figure 2 , and it can be seen that it perfectly reproduces the experimental data, with 1.38 cations over 5 participating to the charge compensation by turning from $2+$ to $3+$ (or an equivalent combination of cations turning from $2+$ to $3+$ and $3+$ to $4+$ ), followed by the formation of oxygen vacancies above this limit.

By comparing the experimental weight loss to the simulation by mechanism 1, which does not involve oxygen vacancies, it is possible to calculate the concentration of oxygen vacancies in the samples as a function of the fraction of lithium (Figure 3).

Surprisingly, some oxygen vacancies are present in the pristine sample (MgCoNiCuZn)O, which may be linked to the possible presence of $\mathrm{Cu}^{+}$. However, the concentration remains low up to $\mathrm{x}=0.20$, as the charge compensation mechanism mostly involves an increase of the valence state of part of the $\mathrm{M}^{2+}$ cations. As expected, the concentration of oxygen vacancies in ( $\left.\mathrm{MgCoNiCuZn}\right)_{1-x} \mathrm{Li}_{x} \mathrm{O}_{1-y}$ increases when $\mathrm{x}$ increases above $\mathrm{x}=0.21$, and reaches quite large values with $\mathrm{y} \approx 0.05$ at $\mathrm{x}=0.3$. Besides the stabilization of the structure owing to the charge compensation coupled to an increase of the entropy of configuration (which in the presence of oxygen vacancies would involve both cationic and anionic sublattices), this large concentration of oxygen vacancies may obviously play a role in the $\mathrm{Li}^{+}$ superionic conductivity and on the dielectric behavior of the compounds.

In order to determine the charge compensation mechanisms at play below $x=0.21$, where the charge compensation only occurs through changes in the valence states of the cations, we have performed XPS analysis of samples with increasing Li content. Figure 4 shows Co- $2 p$ core level XPS spectra for a selection of compositions. For $x=0$, cobalt ions are mainly in the +2 state, although the presence of 
traces of $\mathrm{Co}^{3+}$ cannot be unambiguously excluded. It is possible to distinguish between $\mathrm{Co}^{2+}$ and $\mathrm{Co}^{3+}$ by considering the separation between the main peak, $\operatorname{Co} 2 \mathrm{p}_{3 / 2}$, and its satellites ${ }^{12,13}$. In the case of $\mathrm{Co}^{2+}$ this separation was found to be of about $6 \mathrm{eV}$ while of about $9 \mathrm{eV}$ for $\mathrm{Co}^{3+}$. In addition, spin orbit splitting is different depending on the oxidation state and it goes from $15.8 \mathrm{eV}$ in the case of $\mathrm{Co}^{2+}$ to $15.0 \mathrm{eV}$ for $\mathrm{Co}^{3+14}$.

When increasing the fraction of $\mathrm{Li}^{+}$, the magnitude of the satellite at circa $786 \mathrm{eV}$ monotonically decreases until it completely vanishes at $x \geq 0.15$. Above this value, it is replaced by a small peak at circa $789 \mathrm{eV}$. The magnitude of this peak does not depend on the $\mathrm{Li}^{+}$fraction for $\mathrm{x}>0.15$. Therefore, we can unambiguously confirm that when $\mathrm{Li}^{+}$is introduced in $(\mathrm{MgCoNiCuZn})_{1-\mathrm{x}} \mathrm{Li}_{x} \mathrm{O}, \mathrm{Co}^{2+}$ ions are oxidized into $\mathrm{Co}^{3+}$ to keep the charge balance constant, until all $\mathrm{Co}^{2+}$ in the structure have turned into $\mathrm{Co}^{3+}$ (which occurs at $\left.\mathrm{x}=1 / 6\right)$. No change in the Co $2 \mathrm{p}$ spectra can be observed for concentrations of lithium larger than 0.15 , which indicates that the formation of $\mathrm{Co}^{4+}$ to compensate for the introduction of $\mathrm{Li}^{+}$is unlikely. The binding energies corresponding to $\mathrm{Co}^{3+}$ and $\mathrm{Co}^{4+}$ are very close $\left(779.6 \mathrm{eV}\right.$ and $781.5 \mathrm{eV}$, respectively ${ }^{15}$ ) but the distinction between these two states could be possible by considering the FWHM of the $\mathrm{Co} 2 \mathrm{p}_{3 / 2}$, which was reported as about $2.4 \mathrm{eV}$ for $\mathrm{Co}^{3+}$ and 3.7 eV for $\mathrm{Co}^{4+16}$ with Co cations in a similar chemical environment (Oh geometry).

Figure 5 shows $\mathrm{Ni}-2 p$ core level spectra for a selection of compositions ( $\mathrm{Cu}$ and $\mathrm{Zn}$ spectra are plotted in figures S6 and S7). There is no significant influence of the fraction of $\mathrm{Li}^{+}$on the spectra, which shows that nickel (and copper) ions do not seem to play any role in the charge compensation mechanism occurring upon the incorporation of $\mathrm{Li}^{+}$. The Ni XPS spectra are very similar to $\mathrm{Ni}^{2+}$ in $\mathrm{Oh}$ geometry ${ }^{16,17}$ with a main peak for $\mathrm{Ni}^{2+} 2 \mathrm{p}_{3 / 2}$ at 854.2 to $854.9 \mathrm{eV}$. The apparition of $\mathrm{Ni}^{3+}$ would

This article is protected by copyright. All rights reserved. 
manifest itself by a broadening of the main peak $\left(\mathrm{Ni}^{3+}\right.$ binding energy was reported at $855.2 \mathrm{eV}$ ) together with a decrease of the intensity of the satellites ${ }^{18}$, which is not observed here.

The presence of $\mathrm{Cu}^{+}$in all samples is consistent with the presence of a slight amount of oxygen vacancies even in the Li-free sample, although we cannot totally exclude an in-situ reduction of part of the $\mathrm{Cu}^{2+}$ ions during the XPS measurements.

Considering the results of thermogravimetric analysis and X-ray photoemission spectroscopy, the following mechanism for the charge compensation in $(\mathrm{MgCoNiCuZn})_{1-x} \mathrm{Li}_{x} \mathrm{O}$ can be suggested. First below $\mathrm{x}=1 / 6$, the introduction of $\mathrm{Li}^{+}$leads to the oxidation of $\mathrm{Co}^{2+}$ into $\mathrm{Co}^{3+}$. Then above $\mathrm{x} \approx 0.21$, oxygen vacancies are formed, with a concentration that increases when increasing the fraction of $\mathrm{Li}^{+}$. However, from the present data we are not able to explain how the charge compensation occurs between $\mathrm{x}=1 / 6$ and $\mathrm{x}=0.215$, as the fraction of $\mathrm{Li}^{+}$does not have any influence on the valence state of neither copper nor nickel ions. Some plausible hypotheses can be proposed: either partial oxidation of part of the $\mathrm{Co}^{3+}$ ions into $\mathrm{Co}^{4+}$ could occur above $\mathrm{x}=1 / 6$, with at maximum $38 \%$ of $\mathrm{Co}^{3+}$ turned into $4+$ at $x \approx 0.21$ (which would be hard to detect using XPS). Alternatively, part of the charges could remain uncompensated. As the samples are electrically insulating whatever the fraction of lithium, this hypothesis would require that these charges remain localized, which could be enabled by the huge chemical disorder of the structure. Last, as reported previously (see for instance ${ }^{19}$ ) high oxidation states of $3 \mathrm{~d}$ metals have low lying $3 \mathrm{~d}$ levels and the hybridization of these levels with oxygen $2 p$ orbitals can produce oxygen $p$ holes (ligand holes), which could remain localized in this system due to the large chemical disorder.

This article is protected by copyright. All rights reserved. 
We have shown in a previous study that $(\mathrm{MgCoNiCuZn})_{1-x} \mathrm{Li}_{x} \mathrm{O}$ samples exhibit very large $\mathrm{Li}^{+}$ionic conductivity values, which make them promising for possible applications as solid electrolyte in allsolid-state Li batteries ${ }^{3}$. The ionic conductivity of some samples belonging to the series $(\mathrm{MgCoNiCuZn})_{1-\mathrm{x}} \mathrm{Li}_{\mathrm{x}} \mathrm{O}(\mathrm{x}=0$ to 0.3$)$ is plotted in Figure 6 at selected temperatures, and the corresponding energies of activation are plotted in Figure 7. As the sample $x=0$ does not contain any $\mathrm{Li}^{+}$, the measured conductivity does not correspond to lithium ionic conductivity. The values observed here for this sample are significantly larger than the values reported in our previous study ${ }^{3}$. The difference may originate from the presence of oxygen vacancies in this new sample (see figure3), which could act as donor dopant and lead to a limited electrical conductivity. We tried to fit the temperature dependence of the conductivity of the sample $x=0$ using various models (variable range hopping, small polaron hopping, "simple" semiconductor activation). The resulting fits are plotted in Figures S8-10. The data are well fitted in the temperature range $160-360 \mathrm{~K}$ by either a small polaron hopping or variable range hopping model. However, the fitting parameter leads to an activation energy of $29.5 \mathrm{meV}$ in the former case (one order of magnitude smaller than the values usually observed in the case of transition metal oxides) or to a localization length of $47.6 \mu \mathrm{m}$ in the latter case (even larger than the grains size). In the case of a "simple" semiconductor activation, the fit is not so good $\left(R^{2}=0.973\right)$ and leads to a very small activation energy of $9.7 \mathrm{meV}$. Therefore, further work would be required in order to understand the origin and mechanism(s) of this behavior, which is beyond the scope of this study. In the following, we will thus focus on the Li-containing samples.

As shown in our previous study, the ionic conductivity increases as the fraction of lithium increases, and it reaches very large values when the lithium fraction exceeds $x=0.15$, much larger than the values observed in LiPON in the same temperature range ${ }^{20}$. This increase of the ionic conductivity correlates with a decrease of the activation energy. In our previous study, we proposed that oxygen vacancies might provide a diffusion pathway for $\mathrm{Li}^{+}$ions in the structure. However, although the ionic conductivity increases very rapidly when the fraction of lithium increases up to about $x=0.20$,

This article is protected by copyright. All rights reserved. 
this increase is much slower for larger lithium fraction, and it seems to saturate when $x \geq 0.25$ as the concentration of oxygen vacancies starts to increase. Therefore, it seems that the mechanism of the charge compensation that occurs upon Li substitution has a strong influence on the $\mathrm{Li}^{+}$mobility in the material. More precisely, the presence of large amount of oxygen vacancies seems to have a detrimental effect on the ionic conductivity. Instead of providing a diffusion pathway for $\mathrm{Li}^{+}$ions, oxygen vacancies might constitute trapping centers, or promote the formation of neutral $\mathrm{Li}_{2} \mathrm{OV}_{\mathrm{O}}$ local clusters, thus reducing the actual concentration of mobile $\mathrm{Li}^{+}$. Therefore, further experiments should be performed in order to get a better understanding on the influence of the oxygen vacancies on the lithium mobility. Besides, the control of the oxygen stoichiometry by finely tuning the samples stoichiometry or composition, in order to optimize the concentration and/or localization of oxygen vacancies, should enable to reach even larger ionic conductivity values.

\section{Conclusion}

By combining thermogravimetric analysis and X-ray photoemission spectroscopy, we have shown that the charge compensation that occurs when introducing $\mathrm{Li}^{+}$in the superionic conductor $(\mathrm{MgCoNiCuZn})_{1-x} \mathrm{Li}_{x} \mathrm{O}$ involves several successive mechanisms, that have an unambiguous influence on the magnitude of the ionic mobility. First, for low substitution rates up to $\mathrm{x}=1 / 6, \mathrm{Co}^{2+}$ is gradually oxidized to $\mathrm{Co}^{3+}$, and the actual composition can be written as $(\mathrm{Mg}, \mathrm{Ni}, \mathrm{Cu}, \mathrm{Zn})_{\frac{4(1-x)}{5}} \mathrm{Co}^{I I} \frac{1-6 x}{5} \mathrm{Co}^{I I I}{ }_{x} \mathrm{Li}_{x} \mathrm{O}$. Above $\mathrm{x}=1 / 6$, all $\mathrm{Co}^{2+}$ ions have been turned into $\mathrm{Co}^{3+}$, and another, although unidentified mechanism occurs up to about $x=0.21$. Up to this value, the ionic conductivity increases significantly when the fraction of lithium increases, exceeding $1 \mathrm{mS} . \mathrm{cm}^{-1}$ at room temperature and $20 \mathrm{mS} . \mathrm{cm}^{-1}$ at $100^{\circ} \mathrm{C}$. However, above $\mathrm{x}=0.21$, oxygen vacancies are formed in a significant concentration. From the ionic conductivity measurements, it appears that, counterintuitively, large concentrations of oxygen vacancies are detrimental to the $\mathrm{Li}^{+}$mobility. Therefore, it means that the minimization of the concentration of oxygen vacancies in 
(MgCoNiCuZn $)_{1-x} \mathrm{Li}_{x} \mathrm{O}_{1-\delta}$ through a fine tuning of the composition should enable to reach even larger values of the lithium mobility.

\section{Acknowledgments}

We acknowledge the CNRS PEPS Energie program.

\section{Supporting Information}

- Procedure used to determine the weigh-loss during the synthesis with correction of the hydration of the precursors

- Determination of the activation energy of the conductivity

- Complementary XPS spectra

- Fitting of the temperature dependence of the conductivity of the Li-free sample

\section{References}

1. Motavalli J. Technology: a solid future. Nature. 2015 ;526:S96-S97.

2. Gao Z, Sun H, Fu L, Ye F, Zhang Y, Luo W, et al. Promises, challenges, and recent progress of inorganic solid-state electrolytes for all-solid-state lithium batteries. Adv Mater. 2018; 30:1705702.

3. Bérardan D, Franger $S$, Meena AK, Dragoe N. Room temperature lithium superionic conductivity in high entropy oxides. J Mater Chem A. 2016; 4:9536-9541.

4. Rost CM, Sachet E, Borman T, Moballegh A, Dickey EC, Hou D, et al. Entropy-stabilized oxides. Nat Commun. 2015; 6:8485.

This article is protected by copyright. All rights reserved. 
5. Sarkar A, Djenadic R, Wang D, Hein C, Kautenburger R, Clemens O, et al. Rare earth and transition metal based entropy stabilised perovskite type oxides. J Eur Ceram Soc. 2018; 38:23182327.

6. Jiang $\mathrm{S}, \mathrm{Hu}$ T, Gild J, Zhou N, Nie J, Qin M, et al. A new class of high-entropy perovskite oxides. Scr Mater. 2018; 142:116-120.

7. Chen K, Pei X, Tang L, Cheng H, Li Z, Li C, et al. A five-component entropy-stabilized fluorite oxide. J Eur Ceram Soc. 2018; 38:4161-4164.

8. Bérardan D, Franger S, Dragoe D, Meena AK, Dragoe N. Colossal dielectric constant in high entropy oxides. Phys Stat Solidi RRL. 2016; 10:328-333.

9. Rodriguez-Carvajal J. Recent advances in magnetic structure determination by neutron powder diffraction. Physica B. 1993; 192:55-69.

10. Cherkashinin $\mathrm{G}$, Ensling $\mathrm{D}$, Jaegermann W. $\mathrm{LiMO}_{2}(\mathrm{M}=\mathrm{Ni}$, Co) thin film cathode materials: a correlation between the valence state of transition metals and the electrochemical properties. J Mater Chem A. 2014; 2:3571-3580.

11. Istomin SYa, Karakulina OM, Rozova MG, Kazakov SM, Gippius AA, Antipov EV, et al. Tuning the high-temperature properties of $\mathrm{Pr}_{2} \mathrm{NiO}_{4+\delta}$ by simultaneous $\mathrm{Pr}$ - and Ni-cation replacement. RSC Adv. 2016; 6:33951-33958.

12. Gallant D, Pézolet M, Simard S. Optical and physical properties of cobalt oxide films electrogenerated in bicarbonate aqueous media. J Phys Chem B. 2006; 110:6871-6880.

13. McIntyre NS, Cook MG. X-ray photoelectron studies on some oxides and hydroxides of cobalt, nickel, and copper. Anal Chem. 1975; 47:2208-2213.

14. Chuang TJ, Brundle CR, Rice DW. Interpretation of the X-ray photoemission spectra of cobalt oxides and cobalt oxide surfaces. Surf Sci. 1976; 59:413-429.

15. Dupin JC, Gonbeau D, Benqlilou-Moudden H, Vinatier Ph, Levasseur A. XPS analysis of new lithium cobalt oxide thin-films before and after lithium deintercalation. Thin solid films. 2001; 384:23-32.

This article is protected by copyright. All rights reserved. 
16. Tran N, Croguennec L, Labrugère C, Jordy C, Biensan Ph, Delmas C. Layered $\mathrm{Li}_{1+x}\left(\mathrm{Ni}_{0.425} \mathrm{Mn}_{0.425} \mathrm{Co}_{0.15}\right)_{1-\mathrm{x}} \mathrm{O}_{2}$ positive electrode materials for lithium-ion batteries. J Electrochem Soc. 2006; 153:A261-A269.

17. Kim JG, Pugmire DL, Battaglia D, Langell MA. Analysis of the NiCo2O4 spinel surface with Auger and X-ray photoelectron spectroscopy. Appl Surf Sci. 2000; 165:70-84.

18. Kim KS, Davis RE. Electron spectroscopy of the nickel-oxygen system. J Electron Spectros Relat Phenomena. 1972; 1:251-258.

19. Chen WT, Saito T, Hayashi N, Takano M, Shimakawa Y. Ligand-hole localization in oxides with unusual valence Fe. Sci Rep. 2012; 2:449.

20. Dudney NJ. Addition of a thin-film inorganic solid electrolyte (LiPON) as a protective film in lithium batteries with a liquid electrolyte. J Power Sources. 2000; 89:176-179.

\section{Figures captions:}

Figure 1: Lattice parameter of the series $(\mathrm{MgCoNiCuZn})_{1-\mathrm{x}} \mathrm{Li}_{x} \mathrm{O}(\mathrm{x}=0$ to 0.3$)$. The error bars are smaller than the size of the symbols. The straight lines correspond to linear fits performed either below or above $\mathrm{x}=0.20$.

Figure 2: Weight loss occurring during the synthesis of the samples (MgCoNiCuZn) $)_{1-x} \mathrm{Li}_{x} \mathrm{O}(\mathrm{x}=0$ to 0.3 ). The uncertainty was estimated by measuring 4 samples of same nominal composition. Lines: see text.

Figure 3: concentration of oxygen vacancies as a function of the lithium concentration in $(\mathrm{MgCoNiCuZn})_{1-\mathrm{x}} \mathrm{Li}_{\mathrm{x}} \mathrm{O}_{1-\mathrm{y}}$.

This article is protected by copyright. All rights reserved. 
Figure 4: Co-2p core level XPS spectra for selected compositions from the series $(\mathrm{MgCoNiCuZn})_{1-x} \mathrm{Li}_{x} \mathrm{O}$ $(x=0$ to 0.3$)$

Figure 5: Ni-2p core level XPS spectra for selected compositions from the series ( $\mathrm{MgCoNiCuZn})_{1-x} \mathrm{Li}_{x} \mathrm{O}$ $(x=0$ to 0.3$)$

Figure 6: $\mathrm{DC}$ ionic conductivity for selected compositions from the series ( $\mathrm{MgCoNiCuZn})_{1-\mathrm{x}} \mathrm{Li}_{\mathrm{x}} \mathrm{O}(\mathrm{x}=0$ to $0.3)$

Figure 7: Activation energy of the dc ionic conductivity, for selected compositions from the series (MgCoNiCuZn $)_{1-x} L_{x} \mathrm{O}(x=0$ to 0.3$)$

This article is protected by copyright. All rights reserved. 


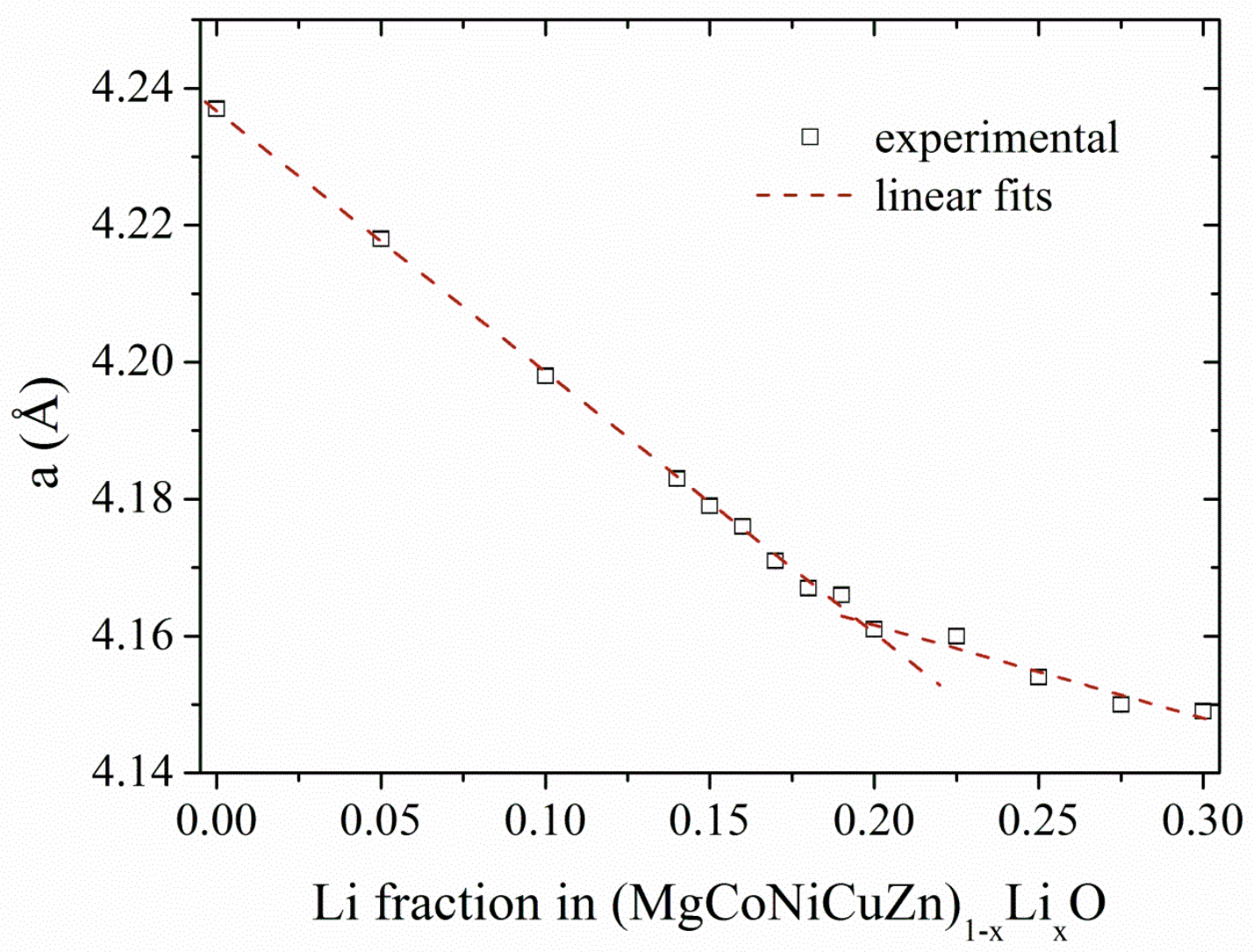

This article is protected by copyright. All rights reserved. 


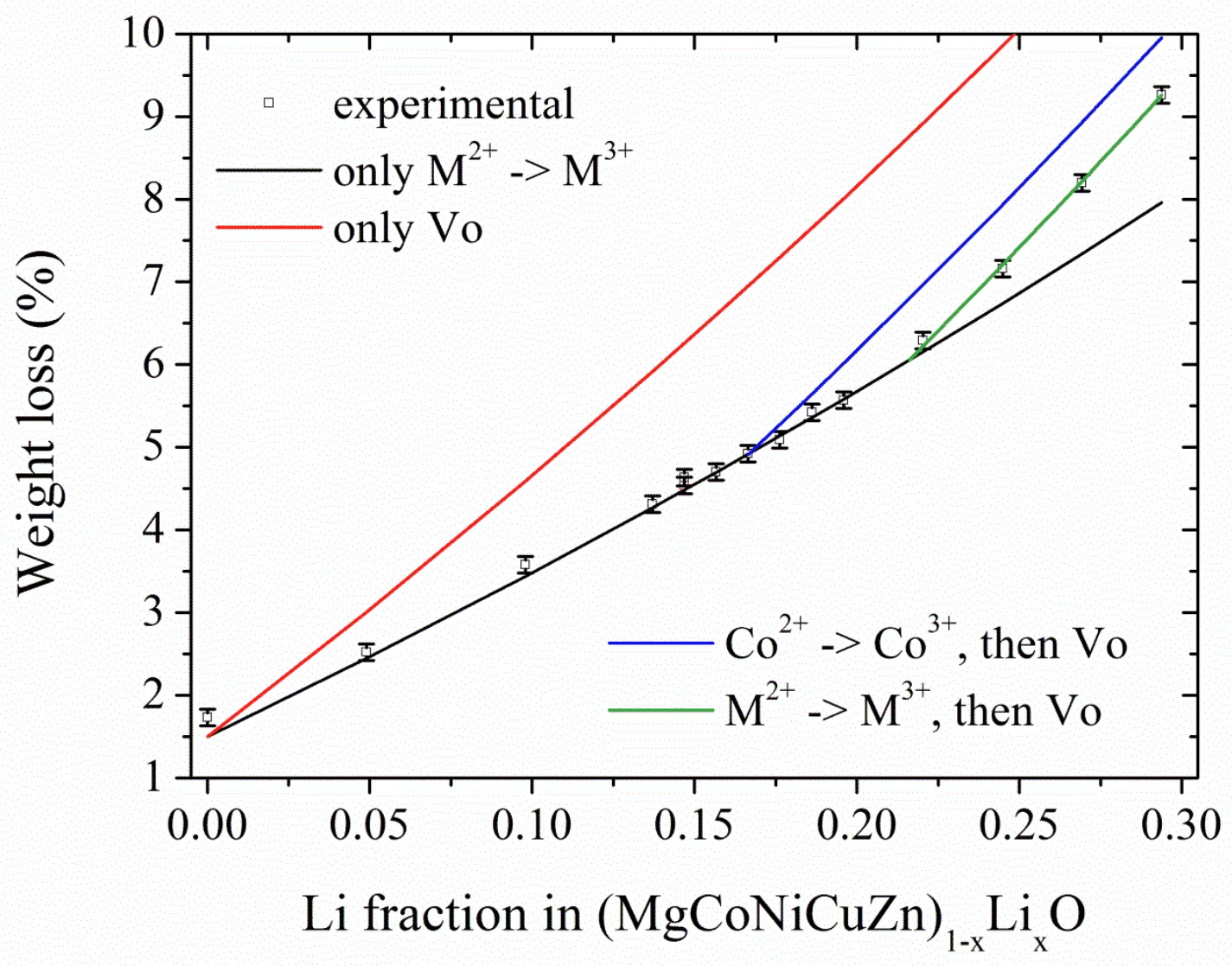

This article is protected by copyright. All rights reserved. 


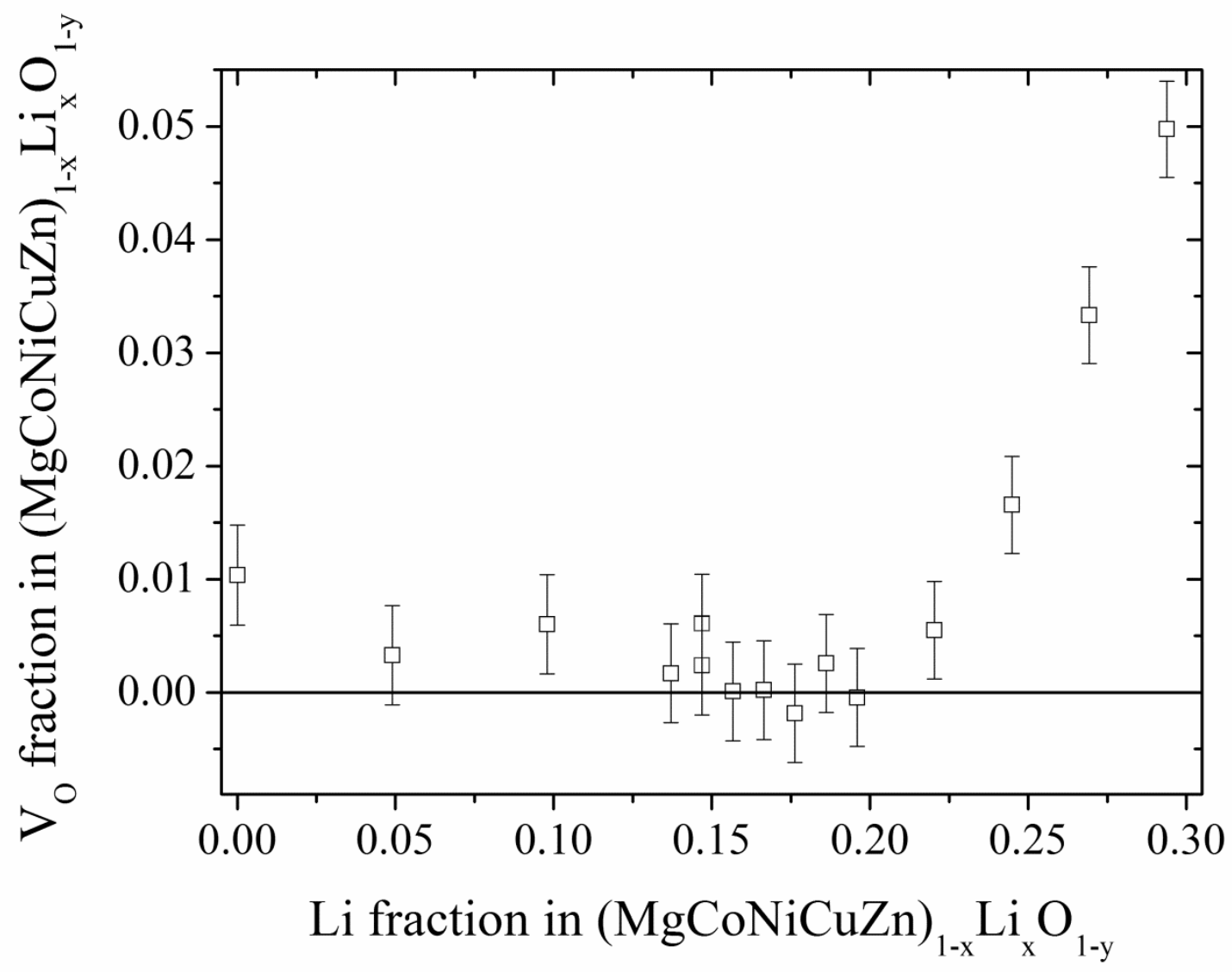

This article is protected by copyright. All rights reserved. 


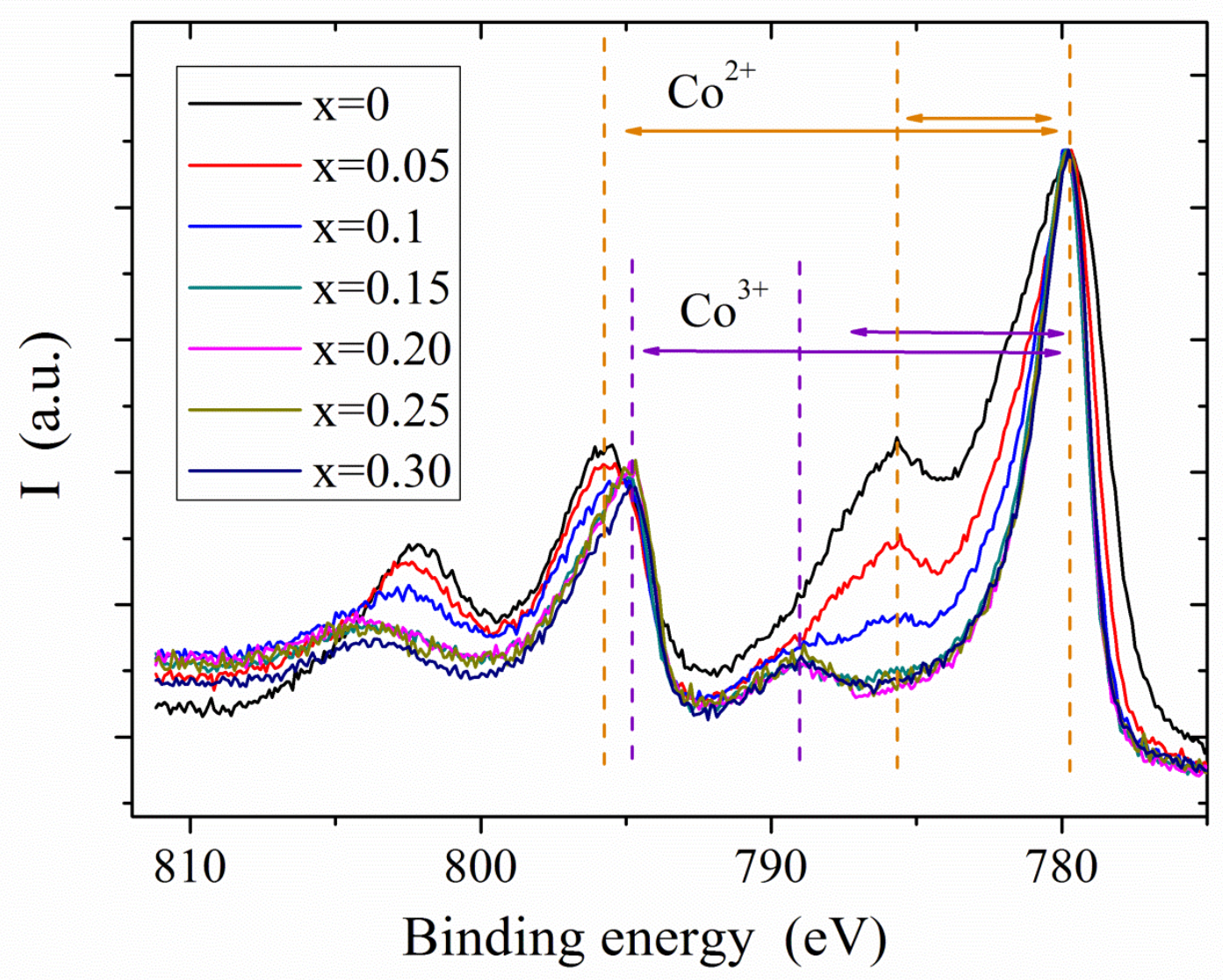

This article is protected by copyright. All rights reserved. 


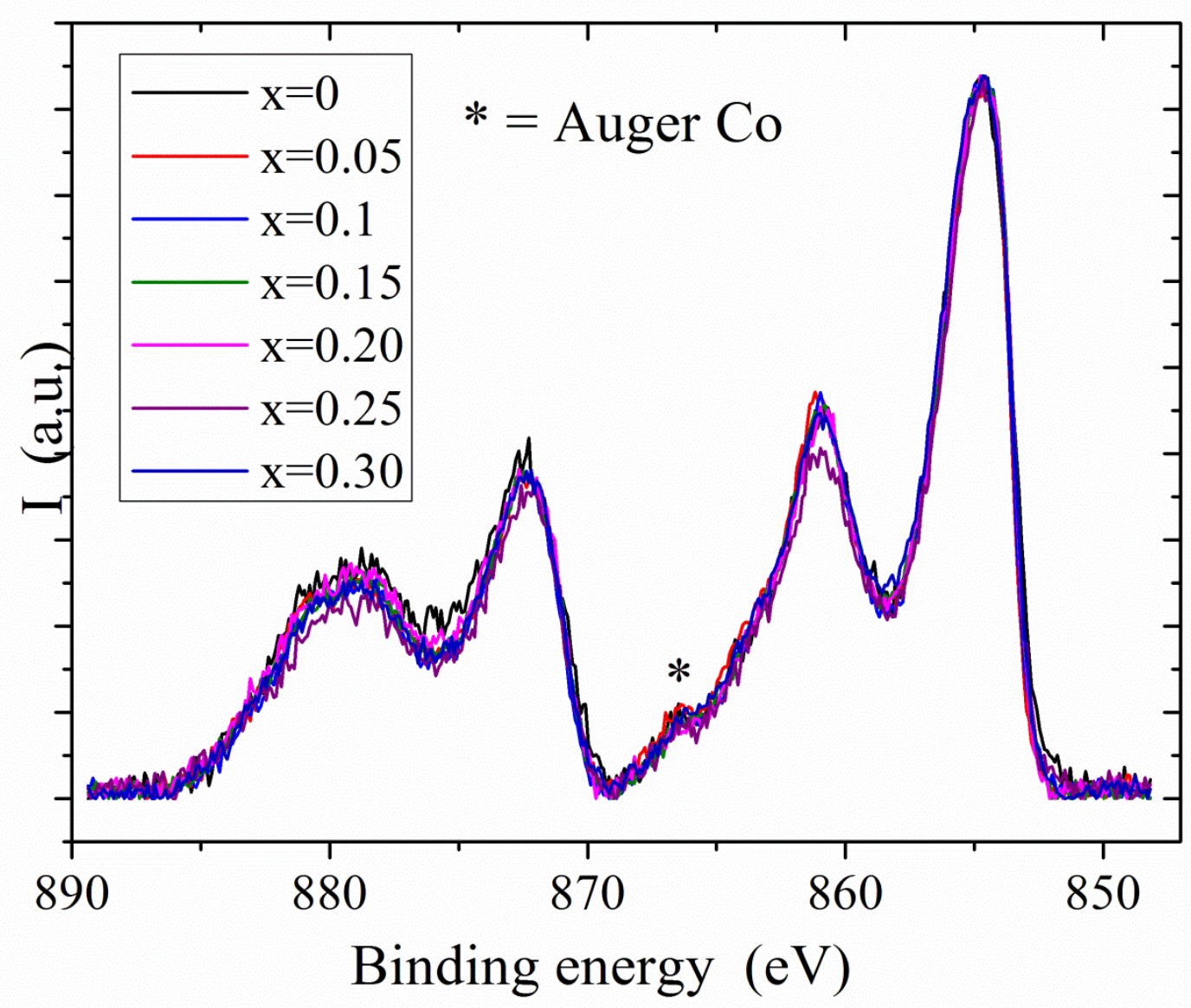

This article is protected by copyright. All rights reserved. 


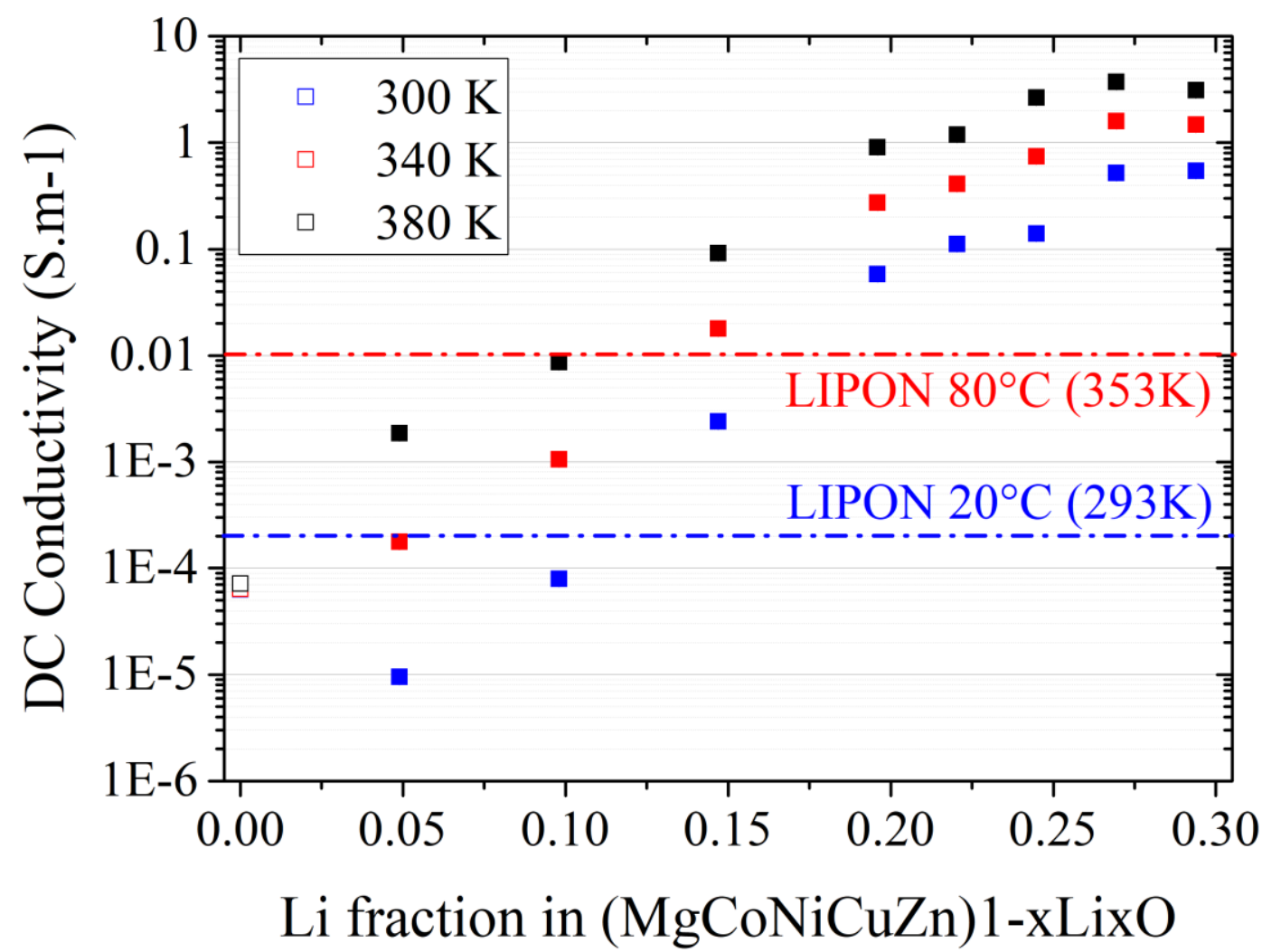

This article is protected by copyright. All rights reserved. 


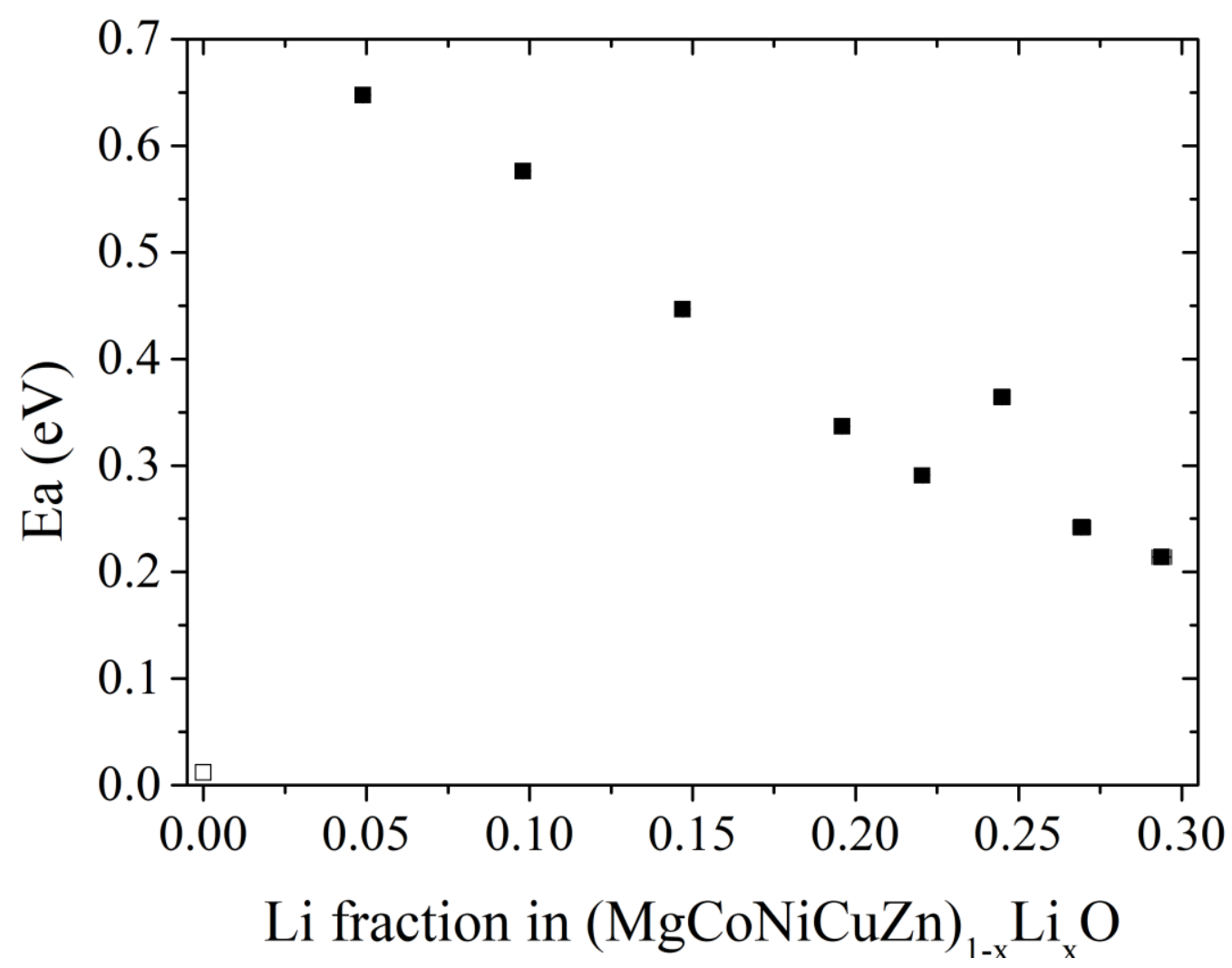

This article is protected by copyright. All rights reserved. 